\title{
An exploration of group-based HIV/AIDS treatment and care models in Sub-Saharan Africa using a realist evaluation (Intervention-Context-Actor-Mechanism- Outcome) heuristic tool: a systematic review
}

Ferdinand C. Mukumbang ${ }^{1,2^{*}}$, Sara Van Belle ${ }^{2}$, Bruno Marchal ${ }^{1,2}$ and Brian van Wyk ${ }^{1}$

\begin{abstract}
Introduction: It is increasingly acknowledged that differentiated care models hold potential to manage large volumes of patients on antiretroviral therapy (ART). Various group-based models of ART service delivery aimed at decongesting local health facilities, encouraging patient retention in care, and enhancing adherence to medication have been implemented across sub-Saharan Africa. Evidence from the literature suggests that these models of ART service delivery are more effective than corresponding facility-based care and superior to individual-based models. Nevertheless, there is little understanding of how these care models work to achieve their intended outcomes. The aim of this study was to review the theories explicating how and why group-based ART models work using a realist evaluation framework.
\end{abstract}

Methods: A systematic review of the literature on group-based ART support models in sub-Saharan Africa was conducted. We searched the Google Scholar and PubMed databases and supplemented these with a reference chase of the identified articles. We applied a theory-driven approach — narrative synthesis - to synthesise the data. Data were analysed using the thematic content analysis method and synthesised according to aspects of the Intervention-Context-Actor-Mechanism-Outcome heuristic-analytic tool-a realist evaluation theory building tool.

Results: Twelve articles reporting primary studies on group-based models of ART service delivery were included in the review. The six studies that employed a quantitative study design failed to identify aspects of the context and mechanisms that work to trigger the outcomes of group-based models. While the other four studies that applied a qualitative and the two using a mixed methods design identified some of the aspects of the context and mechanisms that could trigger the outcomes of group-based ART models, these studies did not explain the relationship(s) between the theory elements and how they interact to produce the outcome(s).

(Continued on next page)

\footnotetext{
* Correspondence: mukumbang@gmail.com

${ }^{1}$ School of Public Health, University of the Western Cape, Cape Town, South Africa

${ }^{2}$ Department of Public Health, Institute of Tropical Medicine, Antwerp, Belgium
} 
(Continued from previous page)

Conclusion: Although we could distill various components of the Intervention-Context-Actor-Mechanism-Outcome analytic tool from different studies exploring group-based programmes, we could not, however, identify a salient programme theory based on the Intervention-Context-Actor-Mechanism-Outcome heuristic analysis. The scientific community, policy makers and programme implementers would benefit more if explanatory findings of how, why, for whom and in what circumstances programmes work are presented rather than just reporting on the outcomes of the interventions.

Keywords: Adherence, Group-based ART model, Antiretroviral therapy, Narrative synthesis, Retention in care, Realist evaluation, Theory-driven review

\section{Background}

Sub-Saharan Africa (SSA) remains the most severely affected region by the HIV and AIDS pandemic, accounting for nearly $71 \%$ of the people living with HIV (PLWHA) worldwide [1]. In response to the hyperepidemics in various countries in this region, and with support from major Global Health Initiatives, HIV treatment programmes-following evidence of the effectiveness of ART-were rapidly expanded from 2005 [2]. Currently, there is evidence that HIV treatment and care can be used to foster the 'test, treat, suppress, and prevent' approach to controlling the HIV pandemic, an approach believed to potentially end AIDS by 2030 .

Antiretroviral treatment (ART) is a 'holistic' treatment approach, whereby taking antiretroviral drugs in compliance with the treatment protocol, eating healthy, and receiving psychosocial support and palliative care is provided as a package [3]. Patients who follow most or all the components of ART have shown improvement in their viral load readings $(<400$ copies $/ \mathrm{mL})$, an increase in the CD4 count $\left(>200\right.$ cells $\left./ \mathrm{mm}^{3}\right)$, a lower incidence of opportunistic infections, and an overall improvement in health [4]. For PLWHA to benefit from all aspects of ART, they must be retained within the care umbrella-that is patients need to be tested for HIV, initiated on treatment, retained in care and reach and maintain viral suppression. Ensuring that patients are retained in care is, therefore, crucial for reaching and maintaining viral suppression and by extension, a successful ART programme [5]. The concept of patientfocused care that has received support for clinic patient management in recent times has promoted individualfocused ART adherence. Nevertheless, it is argued by Haberer et al. that successful population-level ART adherence is pivotal to realising the clinical and prevention benefits of antiretroviral scale-up and consequently ending AIDS by 2030 [6].

As HIV treatment and care programmes mature and extend over the years, the need to ensure long-term retention in care for patients receiving ART while continuing timely initiation of new patients into treatment presents an ongoing challenge to healthcare providers and policy makers [7]. Although the mainstream treatment scheme (facility-based ART services) has gone a long way towards providing the necessary clinical care that patients on ART need to achieve and sustain viral suppression [8], increasing numbers of patients initiated on ART decreases quality care delivery, making it difficult to maintain population-level adherence. It is estimated that in SSA, on average, only $64 \%$ of patients are retained in care after 2 years on ART [9]. Such sub-optimal retention in care rates have implications for the new three-part HIV treatment labelled ' $90-90-90$ ' by 2020 and for the vision to end AIDS by 2030 [10].

Evidence from various studies reveals that task-shifting, where specialist clinical care is delegated to primary health care facilities, makes efficient use of resources without compromising patient outcomes $[11,12]$. Nevertheless, this strategy has a limited capacity to provide long-term resolutions to the challenges of patient retention in care if clinics are overcrowded and waiting times are long, as is often the case in South Africa. Consequently, a continuum of strategies ranging from health service-driven to client-driven options has been developed and implemented to optimise ART delivery in various countries in SSA [13-15].

\section{Alternative antiretroviral treatment models of care}

In responding to the need of scaling up treatment for millions of PLWHA while retaining those already in HIV treatment and care, various differentiated care models have been developed. Differentiated care is defined as 'a client-centred approach that simplifies and adapts HIV services across the cascade to reflect the preferences and expectations of various groups of people living with HIV while reducing unnecessary burdens on the health system' [16].

The standard facility-based care model usually involves patients visiting the health care facility on a monthly basis to be seen by a clinician for routine consultation, and then by a lay counsellor for their drug accountability assessment and counselling. The patient is then provided with one month's supply of medication from the pharmacy. Differentiated care models on the other hand, usually integrate most of the services provided by the standard care model and offer it as a tailored package to the suit 
the needs of different types of patients (patient groups). For instance, patients can be provided with their medication, education and counselling and monitoring services when they are part of a differentiated care model. Differentiated care models are different from mainstream ART service delivery in that they streamline ART services by adapting the care components to the needs of differentiated groups of patients.

Differentiated models usually cover the core activities for providing ART while addressing some of the challenges that patients who use the mainstream clinical care face such as long waiting times, poor access to medication and long distances to the clinic. These differentiated models usually provide minimal clinical screening, quick antiretroviral medication refills, adherence support and defaulter tracing, strict monitoring of attendance and problem-solving, and encouraging self-efficacy and mutual support [17]. Therefore, differentiated models of ART service delivery usually adopt a multifaceted approach towards achieving better adherence and retention in care rates. They increase the capacity and efficiency of ART service delivery by tailoring services according to the needs of different patient groups, reducing clinic contact and relying on community-based services for those who are stable on ART.

Most differentiated care models were developed and implemented by organisations such as Médecins Sans Frontières (MSF) and the AIDS Support Organization (TASO) in collaboration with various local governments in SSA [13]. Following their implementation success in pilot projects, differentiated models are increasingly recognised as an essential approach to managing patients on ART [18]. According to Campion, for these alternative treatment models to be successful, they should ensure that drug delivery is patient-centred, they should fit into the lives of the patients, require minimal time, and they should not be linked to clinical consultations [19].

The new WHO guidelines (2015) highlight the need for differentiated care frameworks with variations in service frequency, health worker cadre, service location and service intensity across countries and populations [18]. Duncombe and colleagues designed a framework for HIV treatment services which identifies variations in the intensity of the core programme components that are tailored to the specific needs of different groups of individuals across the cascade of HIV services [20]. This framework focuses on service intensity of four delivery components: type of services delivered, the location of service delivery, the cadres of health service providers involved, and frequency of visits to health [17]. Fig 1 displays this framework.

Differentiated care can either be healthcare workermanaged groups or client (patient)-managed groups and can either be facility-based individual model or out-offacility individual model [16]. Most individual-focused models of ART service delivery focus on providing psychological support, adherence monitoring and equally address household dynamics potentially impacting on patient adherence [12, 14]. The effects of adherenceenhancing interventions targeting individuals are usually small to modest. Because individual-focused models are usually resource-intensive, they tend to fade over time [21]. While group-based care models offer psychological support and ensure easy access to medication and adherence monitoring, they also create a conducive atmosphere for peer-support among the group members. Individual-focused models such as home-based care [22, 23] and 'accompagnateur' (adherence supporter) [24-26] do not have this aspect of care, except in situations where two or more family members are receiving ART.

Group-based ART delivery models operate on the notion that patients on ART have a mutual self-interest to receive convenient and quality ART services in a conducive and supportive environment, free of stigma and discrimination. To improve the aspect of convenience, most group-based models of ART and HIV care are outof-clinic care models-brought close to patients. Examples of the above mentioned include community ART distribution, community ART groups, and communitybased ART adherence clubs. Table 1 below presents alternative models for the delivery of long-term ART.

The effectiveness of group-based ART models in retaining ART patients in care and improving adherence to medication has been assessed in different studies in SSA. Studies on the community ART group (CAG) model in Tete, Mozambique, have shown better retention in care rates and lower mortality among ART patients enrolled in the CAG model compared to patients in standard facility-based clinical care [27, 28]. Studies on both the facility-based and community-based ART adherence club models in the Western Cape Province of South Africa have shown better retention in care and adherence to medication rates among patients compared to those patients in standard ART care [29, 30]. Also, based on the findings of a systematic review to assess the effectiveness of group-based adherence models of care, it was concluded that community support programmes could be an effective strategy to improve the effectiveness of ART treatment and care in SSA and elsewhere [31].

It is argued by Chen [32] that theory-driven approaches to programme development improve implementation. The theoretical understanding of how and why individual-focused interventions work has been explored previously using various health behaviour theories [33]. On the other hand, because group-based ART 


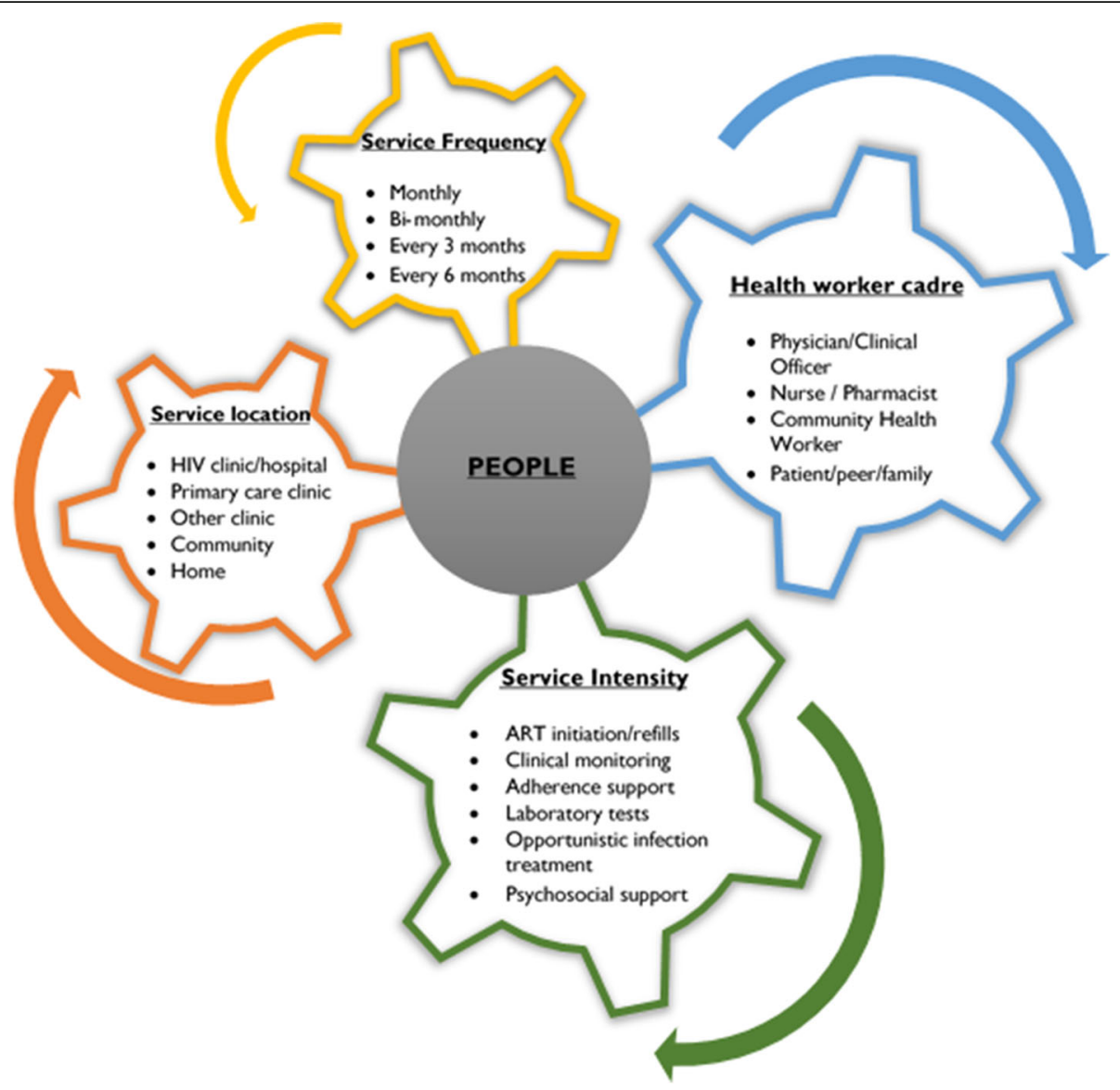

Fig. 1 A framework for differentiated models of ART services (Adapted from Duncombe et al. [17])

interventions models are complex-typically multicomponent and context-dependent-they are challenging to replicate and evaluate [34]. In most instances, not even the programme theories-an explicit theory or model of how an intervention contributes to a set of specific outcomes [35] — of group-based ART interventions models are described. Therefore, our understanding of how and why group-based ART models achieve better adherence and retention in care rates within their context is limited. To this end, we aimed to review primary studies systematically and develop a narrative synthesis of the mechanism(s) at work during the implementation of group-based interventions for ART adherence support. Identifying the causal mechanisms of group-based ART models is the precursor step in developing programme theories that explain how and why group-based ART treatment and care models work, for which ART population group and under what circumstances.

There are three steps in eliciting a programme theory in realist evaluation [36]. Step 1 entails conducting an exploratory qualitative study to identify the assumptions of the programme designers and health service managers on how and why the adherence club intervention is expected to achieve its goals and perceptions on how it has done so. These assumptions are also called 'folk theories' [37]. In the second step, we reviewed theories on ART adherence to identify candidate/potential mechanisms provided by ART interventions [38]. The third step, which is the focus of this paper, involves assessing the evidence on how and why group-based ART adherence interventions work by examining their underlining theories using the context-mechanism-outcome (CMO) heuristic - a realist evaluation analytic tool.

\section{Review questions}

Three research questions guided the review:

1. What are the key mechanisms that drive the outcomes of group-based ART adherence interventions?

2. What are the contextual factors that influence the triggering of mechanisms, the implementation and the outcomes of group-based ART adherence interventions? 
Table 1 Summary of strategies for differentiated models for delivery of long-term ART [13, 20]

\begin{tabular}{|c|c|c|c|c|c|c|}
\hline \multicolumn{2}{|c|}{ Key objective } & \multicolumn{2}{|l|}{ ART adherence clubs } & \multirow[t]{2}{*}{ CADP } & \multirow[t]{2}{*}{ CAG } & \multirow[t]{2}{*}{$\mathrm{CHBC}$} \\
\hline & & Facility-based club & Community-based club & & & \\
\hline \multirow[t]{3}{*}{$\begin{array}{l}\text { Patient } \\
\text { perspective }\end{array}$} & $\begin{array}{l}\text { Reduce cost } \\
\text { (time + transport) }\end{array}$ & $\begin{array}{l}\text { - Reduction of clinical } \\
\text { visit } \\
\text { - Less time spent at } \\
\text { clinic for drug refill }\end{array}$ & $\begin{array}{l}\text { - Reduction of } \\
\text { clinical visit } \\
\text { - Less time spent a } \\
\text { clinic for drug refill }\end{array}$ & $\begin{array}{l}\text { - Reduction of } \\
\text { clinical visit } \\
\text { - Less time spent at } \\
\text { clinic for drug refill }\end{array}$ & $\begin{array}{l}\text { - Reduction of } \\
\text { clinical visit } \\
\text { - Less time spent } \\
\text { at clinic for } \\
\text { drug refill }\end{array}$ & $\begin{array}{l}\text { - Reduction } \\
\text { of clinical } \\
\text { visit } \\
\text { - Less time } \\
\text { spent at } \\
\text { clinic for } \\
\text { drug refill }\end{array}$ \\
\hline & $\begin{array}{l}\text { Increase peer } \\
\text { support }\end{array}$ & $\begin{array}{l}\text { At club in health } \\
\text { facility and } \\
\text { potentially beyond } \\
\text { into community }\end{array}$ & $\begin{array}{l}\text { At club in community } \\
\text { and beyond }\end{array}$ & $\begin{array}{l}\text { At distribution points } \\
\text { by expert patients }\end{array}$ & $\begin{array}{l}\text { At CAG meetings } \\
\text { in community } \\
\text { and beyond }\end{array}$ & $\begin{array}{l}\text { At } \mathrm{HBC} \\
\text { meetings by } \\
\text { the CHWs }\end{array}$ \\
\hline & $\begin{array}{l}\text { Enhance } \\
\text { community } \\
\text { participation }\end{array}$ & No & Potentially & Potentially & Potentially & Potentially \\
\hline \multirow{9}{*}{$\begin{array}{l}\text { Healthcare } \\
\text { service } \\
\text { perspective }\end{array}$} & Reduce workload & & & & & \\
\hline & - Nurse & Yes & Yes & Yes & Yes & Yes \\
\hline & - Pharmacist & No & No & Yes & Yes & Yes \\
\hline & $\begin{array}{l}\text { - Counsellor/ } \\
\text { CHW expert } \\
\text { patient }\end{array}$ & $\begin{array}{l}\text { No (facilitation } \\
\text { by club) }\end{array}$ & $\begin{array}{l}\text { No (facilitation } \\
\text { by club) }\end{array}$ & $\begin{array}{l}\text { No (Distribution } \\
\text { and monitoring) }\end{array}$ & $\begin{array}{l}\text { No (formation, } \\
\text { training and } \\
\text { supervision of } \\
\text { CAGs) }\end{array}$ & $\begin{array}{l}\text { No } \\
\text { (formation, } \\
\text { training } \\
\text { and } \\
\text { supervision } \\
\text { of HBC) }\end{array}$ \\
\hline & $\begin{array}{l}\text { Maintain/improve } \\
\text { health outcomes }\end{array}$ & & & & & \\
\hline & - Adherence & Yes & Yes & Unknown & Unknown & Unknown \\
\hline & - Retention & Yes & Yes & Yes & Yes & Yes \\
\hline & $\begin{array}{l}\text { Improve } \\
\text { self-management } \\
\text { of patient }\end{array}$ & $\begin{array}{l}\text { Adherence } \\
\text { support }\end{array}$ & $\begin{array}{l}\text { Adherence } \\
\text { support and } \\
\text { tracing }\end{array}$ & $\begin{array}{l}\text { Organisation of service for } \\
\text { drug refill, adherence support, } \\
\text { tracing and testing }\end{array}$ & $\begin{array}{l}\text { Drug refill, } \\
\text { adherence support, } \\
\text { tracing and testing }\end{array}$ & $\begin{array}{l}\text { Adherence } \\
\text { support } \\
\text { and tracing }\end{array}$ \\
\hline & Decongest facility & No & Yes & Yes & Yes & Yes \\
\hline
\end{tabular}

CADP community ART distribution point, CAG community ART groups, CHBC community home-based care

3. Are there identifiable pathways to the outcomes? If so, how do the key mechanisms and contexts interact to produce these outcomes?

\section{Realist evaluation and generative mechanisms}

Realist evaluation is underpinned by a 'generative' model of causality [38]. Identifying the 'generative mechanism' is at the core of eliciting the programme theory. Generative mechanisms describe the causal forces, powers, processes or interactions that generate change within an intervention-including the choices, reasoning and decisions that people make as a result of the resources provided by the programme. Therefore, the key explanatory element in realist evaluation is the generative mechanism, which elucidates the reasoning the actors attribute to the resources, opportunities and/or restraints provided by the intervention that leads to action. A generative mechanism in realist logic is thus mathematically represented as:

Resources (constraints and/or opportunity) + Reasoning $=$ Mechanism [39].
The same mechanism can produce different results in different contexts (Fig 2). This suggests that while the same intervention might instigate the same mecha$\operatorname{nism}(\mathrm{s})$, the differences in the outcome(s) of an intervention in different settings could be largely associated with the differences in the context within which the intervention is implemented. For instance, if 'motivation' (mechanism) is stimulated by adherence counselling and educational talks (intervention), to improve ART adherence (outcome) among PLWHA (actors), then possible context variations could include the pre-existing group dynamics within the adherence club, the local socioeconomic conditions, the local cultural norms, the geographical accessibility of the club, etc. The educational level of patients, the meaning they attach to their disease, and the way they cope with it are examples of other patient-related factors that are likely to vary substantially. The level of adherence to medication and retention in care in the different contexts represented by different health care facilities depends on how much the 


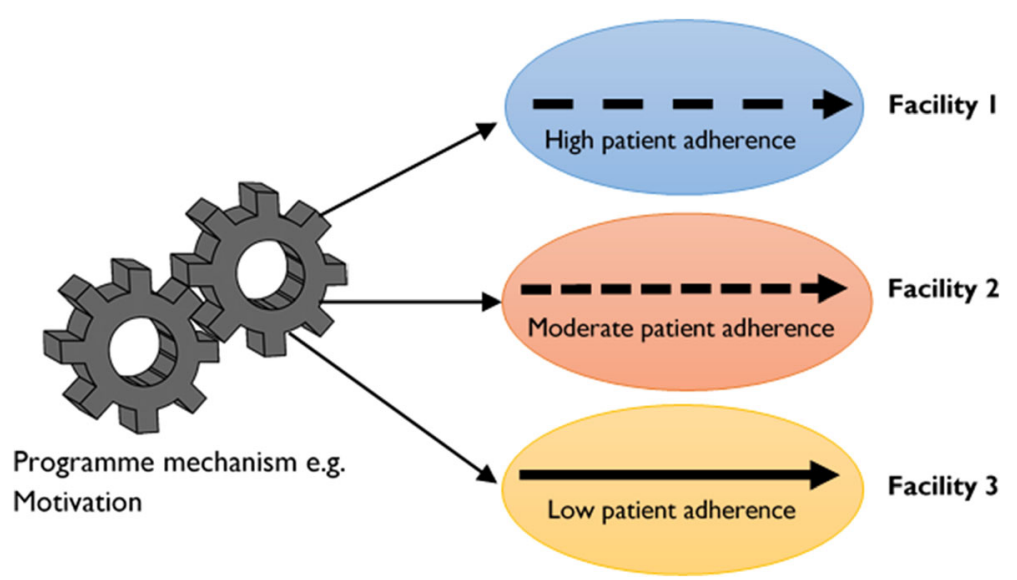

Fig. 2 The same mechanism is postulated as generating contrasting outcomes

motivation is triggered by the intervention and modified by the various context conditions.

Formulating an initial programme theory in realist evaluation involves adopting a 'generative' approach to causation. Pawson and Tilley [37] identified context, mechanisms and outcomes as the three tenets to explaining how and why programmes work or not with the notion that an outcome $(\mathrm{O})$ is generated by a mechanism $(\mathrm{M})$ being triggered in context $(\mathrm{C})$. Considering that an intervention works through actors, generative mechanisms $(\mathrm{M})$ are used to explain how the intervention (I) (or aspects of the intervention) unfolds in a particular context $(\mathrm{C})$ and in relation to the various actors (A) to produce the observed outcomes $(\mathrm{O})$. Representing the intervention modalities (I) and the relevant actors (A) provides a comprehensive representation of how, why, for whom and under what circumstances a programme works (or not) [40]. Following this causality conceptualisation, we considered an interventioncontext-actor-mechanism-outcome (ICAMO) configuration to provide a comprehensive analytical tool to account for (or explain) aspects of the intervention that provide the mechanisms and the actors through whom the intervention works. In this article, we adopted the ICAMO heuristic tool for the analysis purpose.

To explore the potential generative mechanisms that group-based ART models could provide through their various modalities, we carried out a narrative synthesis of the literature, a theory-based review approach, which allows us to explore components of the intervention implementation to identify their underlining theory or theories. This study was conducted as part of larger research project 'A realist evaluation of the antiretroviral treatment adherence club programme in selected primary health care facilities in the metropolitan area of Western Cape Province, South Africa' [41]. The first phase of this project involves eliciting the initial programme theory of the adherence club interventionwhat aspects of antiretroviral club intervention work, for what sections of the patient population, and under which community and health systems contexts. An important part of eliciting the initial programme theory is reviewing the literature on how similar interventions that have been implemented are postulated to work, why they work, for whom they work and under what circumstances [42], and this paper presents the findings of that step.

\section{Methods \\ Study design}

We used narrative synthesis (NS) - an approach used to systematically review and synthesise findings from multiple studies. It relies primarily on the use of narratives to summarise and explain the findings of a synthesis [43]. NS is applied when statistical meta-analysis (for quantitative studies) or meta-ethnography (for qualitative analysis) is not possible and when the existing literature includes a wide range of interventions and studies with different (study) designs, which because of the heterogeneity cannot be pooled for analysis [43, 44]. Pawson and colleagues [45] suggested that theory-driven reviews are more fruitful approaches to reviewing evidence when evaluating competing interventions addressing the same problem.

NS fits with the logic of realist evaluation-NS requires the reviewer(s) to develop a theory of how the intervention in question works, why and for whom [43]. NS is recommended for reviews addressing questions on the effects of interventions, particularly, the implementation of interventions that are proven to be effective in experimental settings [46]. NS suits the study because most group-based ART interventions have been shown to be effective in pilot studies, a recommendation for its use $[43,46]$. Finally, the heterogeneity of the literature 
on group-based ART interventions warrants the use of narrative reviews.

NS also fits in with the formulation of the initial programme theory as conceived by realists. The guidance on NS in systematic reviews focuses on the effects of interventions ('outcomes') and the factors influencing intervention implementation (which aligns with the notions of 'mechanism' and 'context'). This approach is thus well-matched with the realist logic. According to Arai and colleagues [46], the 'theory of change' identified in the first step of a NS provides a way for abstracting the mechanisms into propositions at the end of the synthesis process. Finally, NS is aligned with the epistemological position of realist evaluation.

\section{Identification and selection of studies}

The search process proceeded in two phases. First, we conducted an exploratory search to enable us to make an initial judgement on the availability of evidence to answer the review questions. Second, after confirming that there is adequate literature, we searched for primary research studies for possible inclusion in the review. We applied two methods to search for literature: electronic database searching (PubMed and Google Scholar) using keywords and snowballing of citations from the reference list of other authors. The goal was to find primary studies that shed light on the explanatory model of how the group-based ART models work.

The following search MeSH terms were used for the search of the electronic databases: 'community-based antiretroviral therapy programme', 'group-based antiretroviral therapy', 'Interventions to improve adherence to antiretroviral therapy and retention in care, 'Implementation of community-based antiretroviral therapy programmes', 'Effectiveness of antiretroviral treatment and care interventions', 'Differentiated antiretroviral treatment models,' 'Alternative antiretroviral therapy interventions', 'Group-based adherence intervention to antiretroviral therapy', 'Qualitative evaluation of groupbased models' and 'in Sub-Saharan Africa'. Figure 3 presents the search process.

\section{Inclusion criteria}

We defined the inclusion criteria for the study selection of the review using the SPIDER (Sample, Phenomenon of Interest, Design, Evaluation, Research type) mnemonics for qualitative reviews [47].

- Sample: Stable adult (18+ years) patients on ART

- Phenomenon of Interest: Retention in care and adherence to antiretroviral medication

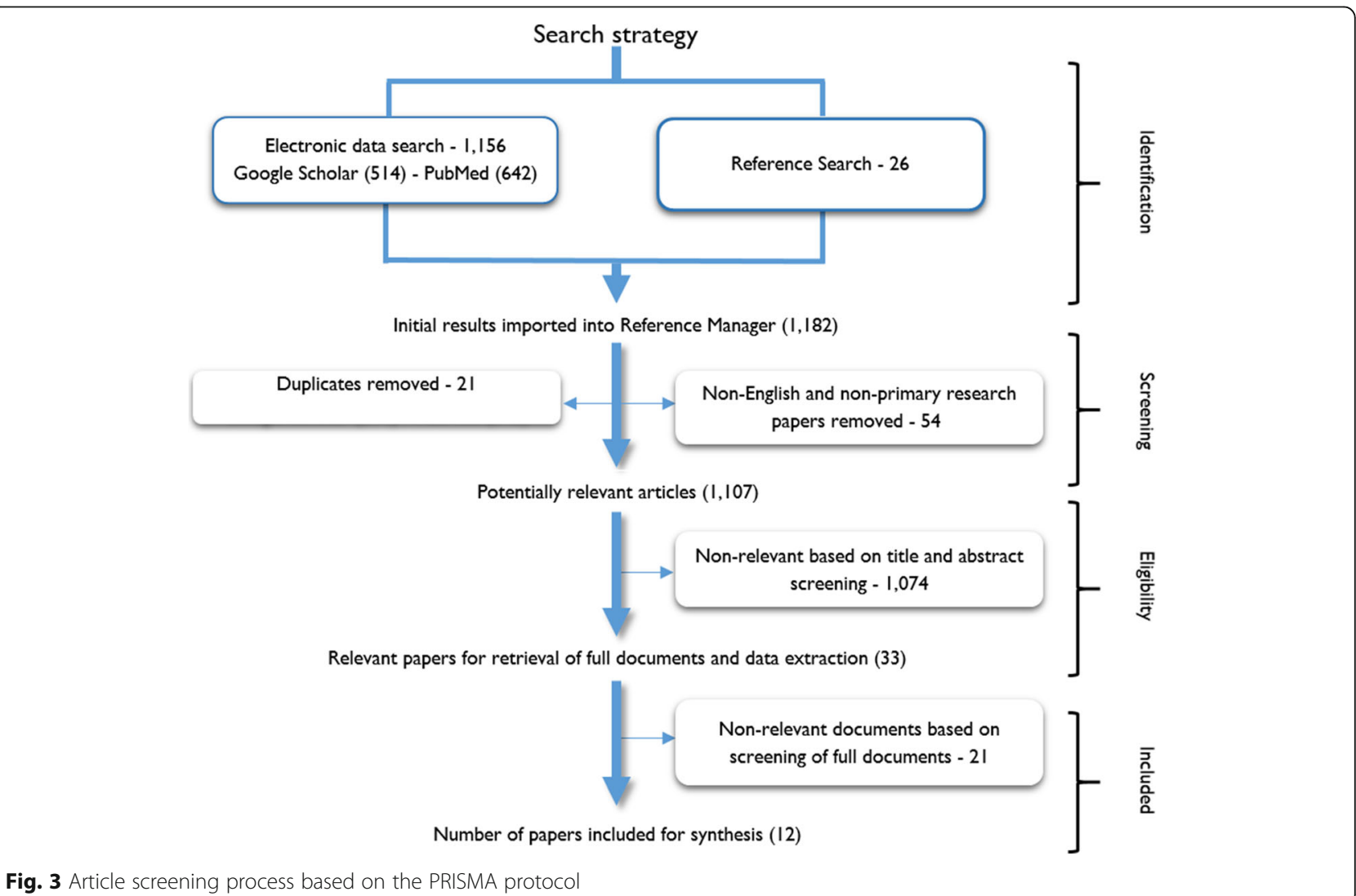


- Design: Quantitative, qualitative and mixed-methods studies

- Exposure: Facility-based and community-based group-ART models in SSA

- Research type: Primary research articles on groupbased ART models

\section{Exclusion criteria}

- All articles that did not deal with a group-based ART model of treatment and care such as homebased care models.

- Non-English papers

- Papers reporting non-primary research

We used the ReadCube ${ }^{\circ}$ Reference Management system to screen and manage the retrieval of the studies. The search was conducted in February 2016 and updated in April 2017. The date limit set on the records to search was 2005-2016 because group-based ART management models only emerged in the early 2000 s.

\section{Ethical considerations}

This study is part of a larger project 'A realist evaluation of the antiretroviral treatment adherence club programme in selected primary health care facilities in the metropolitan area of Western Cape Province, South Africa' which has received ethics clearance from the Higher Degree's committee of the University of the
Western Cape [41]. In addition, we followed the relevant standards of utility, usefulness, feasibility, propriety, accuracy and accountability while conducting the review [48].

\section{Data analysis-analysing the papers for the narrative synthesis}

Conducting a NS involves four distinct but interrelated steps [43]:

- Developing a theory of how the intervention works, why and for whom

- Developing a preliminary synthesis of findings of included studies

- Exploring relationships in the data

- Assessing the robustness of the synthesis

\section{Step 1. Developing a theory of how the intervention works,} why and for whom

We developed a theory on how the intervention under investigation works, why and for whom. This tentative theory is meant to guide the synthesis process and is to be refined at the end of the synthesis. We formulated an initial theory guiding this synthesis (Fig. 4) based on the principles of group-based ART models as outlined in the standards of practice of some of these group-based models $[20,49]$ and the folk theories that we formulated from the consultation with the adherence club programme designers and managers [50]. Group-based

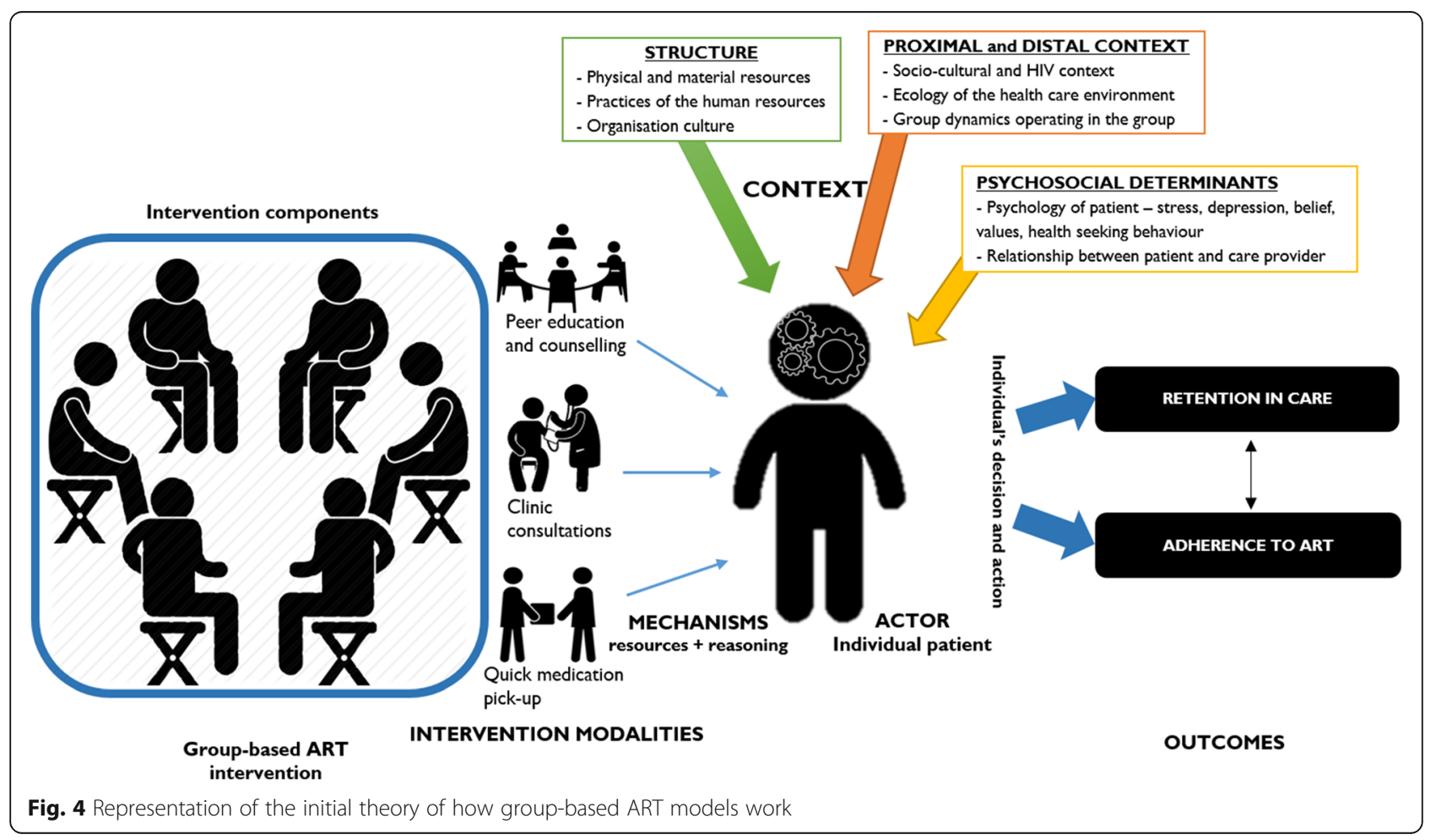


models of ART services have some basic principles guiding their implementation:

- Task-shifting of services to the lowest level of care provider, from nurses offering ART services to community health workers and in some instances to PLWHA (expert patients).

- Adherence is improved by decreasing the burden placed on patients (time, cost, pills) and by increasing the user-friendliness of care and treatment services.

- Having patients receive their care together to increase peer support among the patients and creating an enabling treatment and care environment.

- By separating the drug-delivery and clinical care and reducing the intensity of the services, the care process is simplified for the providers and made much user-friendly.

We associated the generic components of group-based ART intervention (intervention modalities, actors, context, mechanisms and outcomes) to formulate the initial theory (Fig. 4). The primary outcomes are adherence to medication and retention in care. The mechanisms were derived from underlying determinants or social behaviours identified in the folk theories and included motivation, trust, encouragement, social support, self-efficacy and buy-in. These mechanisms are expected to be triggered by the various programme components within the immediate (micro), organisational (meso) and distal contexts (macro) [51]. The contextual factors include human resources (staffing dynamics), stakeholder collaboration, availability of conducive physical space and support from the higher level of the organisation. The dashed lines in Fig. 4 indicate that the context goes beyond the immediate environment where the intervention is being implemented, including the organisational and the distal context.

\section{Data analysis/synthesis}

Step 2. Developing a preliminary synthesis-extracting data from the included studies

In the second step, we extracted the data according to the following categories were used: (1) publication citation, (2) study country, (3) participants and setting where the study was conducted, (4) study design, (5) implementation setting and (6) description of the outcome (Table 2).

Twelve articles representing six studies were identified. Seven of the studies were on the community ART group (CAG) intervention. Five of the studies' settings were Tete, Mozambique [27, 52-55], one was in Lesotho [56] and the other one was in Rwanda [57]. Three of the studies examined an ART adherence club intervention implemented in South Africa [29, 30, 58]. Two studies in Kenya focused on the Medication Adherence Club implemented in Nairobi, Kenya [59, 60].

\section{Results}

\section{Step 3. Exploring relationships in the data and between} studies: a realist perspective

We applied a two-phase process guided by realist evaluation principles (represented in step three in the synthesis process in Fig. 5).

First, we applied the thematic content analysis approach to systematically identify recurrent or salient themes across the selected studies. This was guided by core elements of the initial programme theory (see Additional file 1 for coding framework) (Table 3).

Following the thematic analysis, we explored the theoretical propositions assumed to represent the functioning of group-based ART models within each paper. First, we searched for the components of intervention, actors, context, mechanism and outcome within each article as they describe the group-based intervention in question. We found that the studies included for the review adequately described the intervention(s) under evaluation and their modalities. Similarly, the actors in the various studies were clearly identified in terms of the patient profiles, also the outcomes were well identified. Concerning the context, however, we observed that some studies provide more information than others but generally, there was a minimal structured discussion. Finally, virtually no paper presented a clear discussion on the generative mechanisms underlying the intervention under investigation. Indeed, we observed that all studies that only applied a quantitative research approach either failed to identify possible mechanisms or only identified a few $[29,30,52,53,57,60]$. Very few studies identified some contextual factors around the implementation of group-based adherence models [54, 59, 60].

Because the studies that applied a quantitative design provided little or no information on the possible mechanisms and context conditions that explain the outcomes of the intervention, they provide little information that could help to theorise how group-based interventions work. The qualitative studies $[27,55,58,59]$ and the mix-method studies $[54,56]$ on the other hand, offered more information on the context, mechanism(s) and outcomes. Nevertheless, most of the information from the qualitative studies were produced by three studies conducted by the same group of authors evaluating a singular intervention (community adherence group) from different perspectives and another group of authors evaluating the Medication Adherence Clubs. These qualitative studies identified potential mechanisms and 


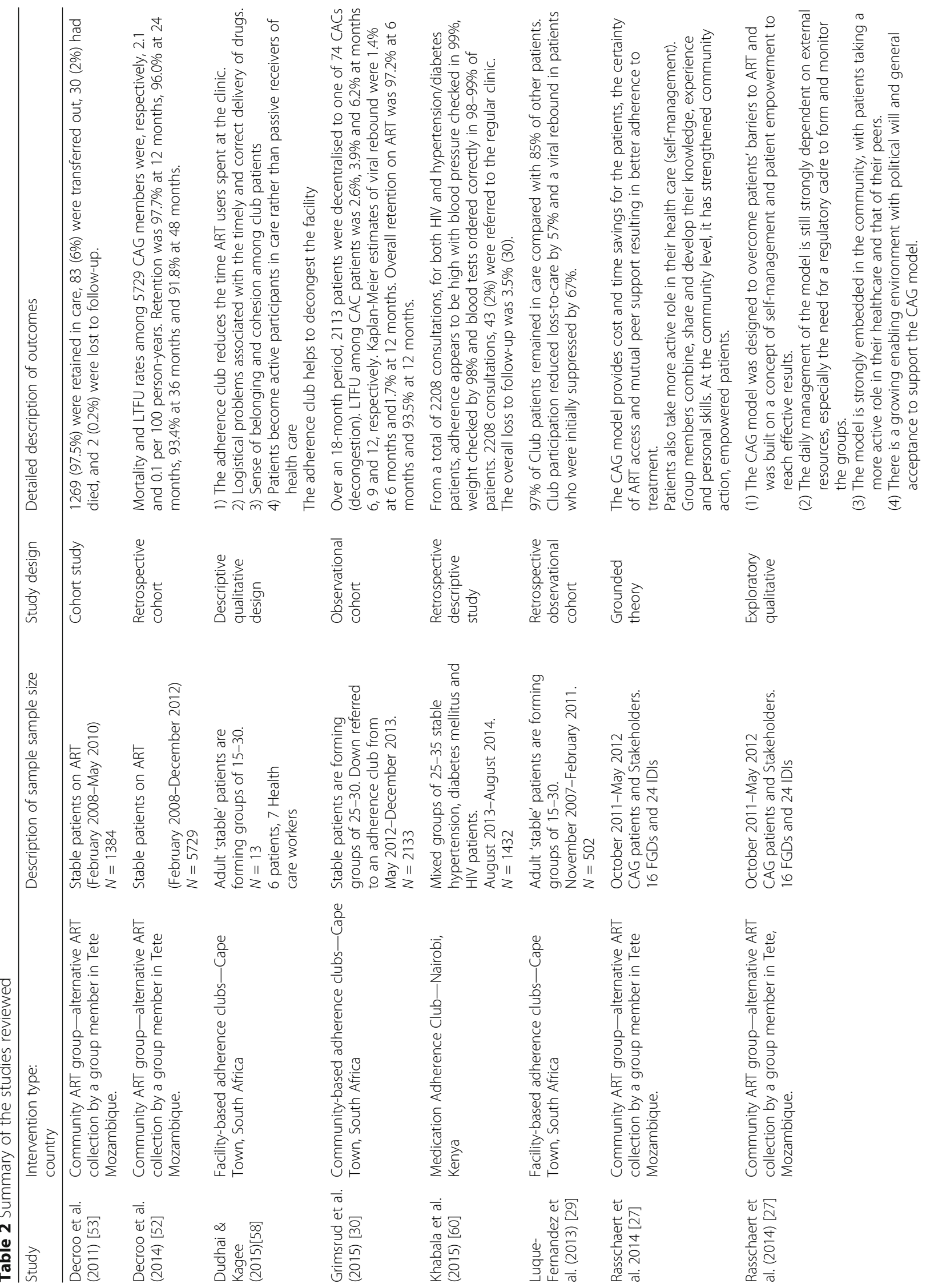


Mukumbang et al. Implementation Science (2017) 12:107

Page 11 of 20

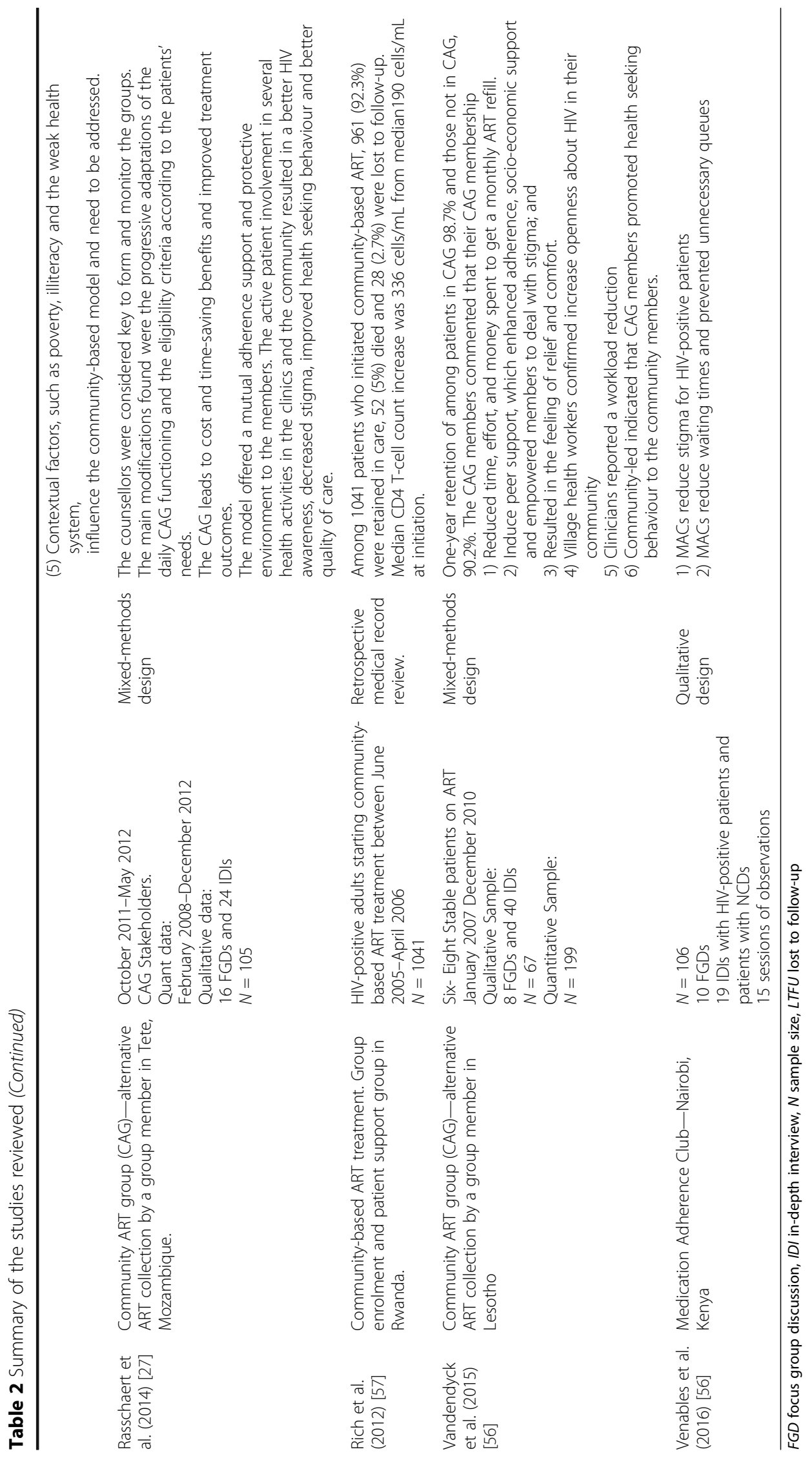




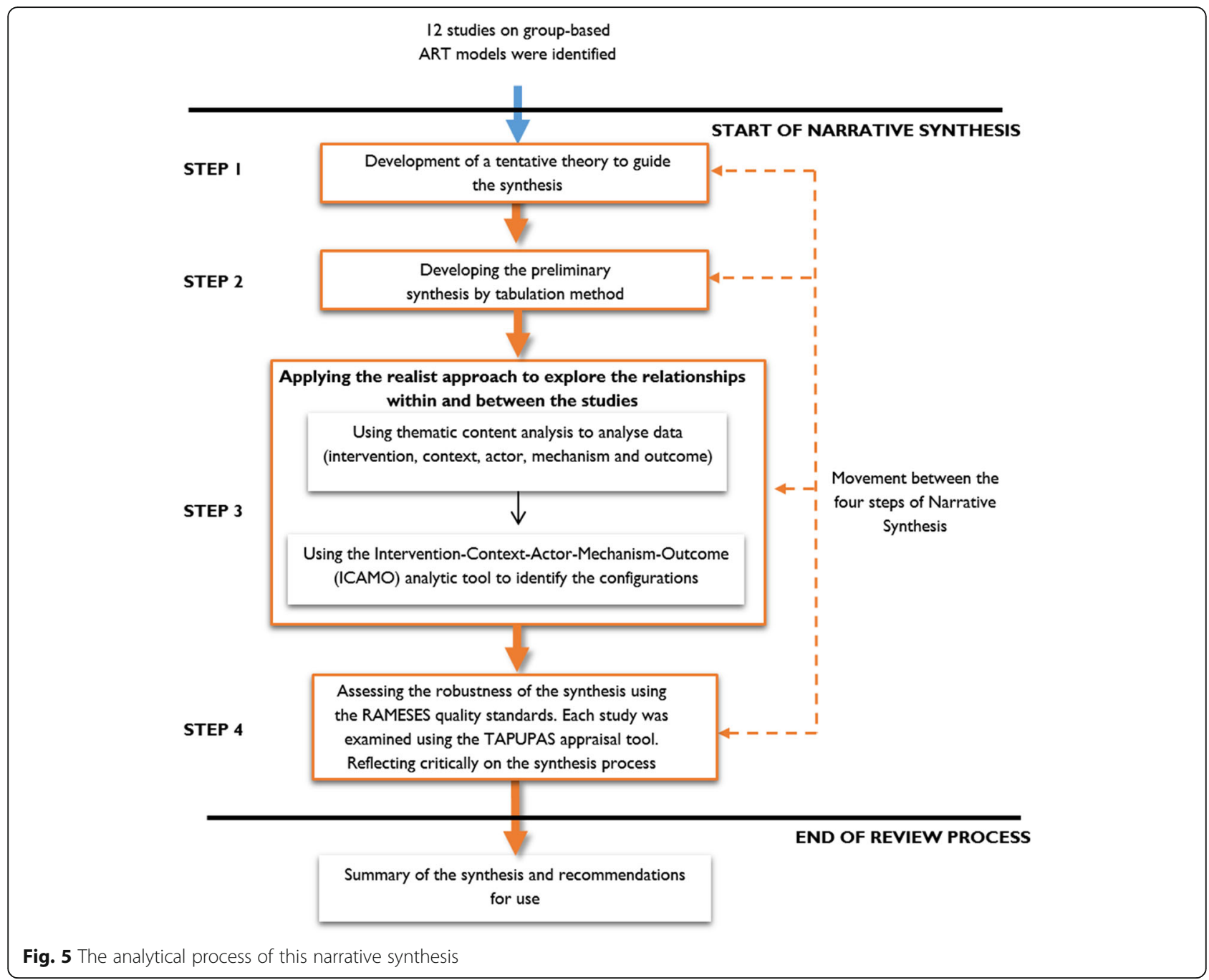

aspects of the context that could help explain the outcomes of the group-based models. Mechanisms identified from the selected studies include [perceived] social support (mutual adherence support), acceptability related to perceived advantages, empowerment, patient satisfaction, bonding among group members (trusting relationship), motivation, and increased assurance. However, none of the studies explored or demonstrated a relational association between the intervention, context, mechanism and outcomes nor did the studies show a causal explanation of how, why, for whom and under what circumstances do the interventions under investigation work (or not).

In summary, different studies identified different components of the ICAMO heuristic-analytic tool. Most of the studies did not identify all the components of the ICAMO heuristic tool. This was especially common with the studies that adopted the quantitative study approach. While some of the qualitative and mixed-methods studies identified most or all of the components of the ICAMO heuristic tool, none of the studies provided a conceptualised causal link of these components to explain how and why the interventions work in the context in which they are implemented.

\section{Rigour and trustworthiness}

Step 4. Assessing the robustness of the synthesis

The inclusion of articles for the review process was based on two criteria: relevance and rigour. The RAMESES quality standards guided the quality assessment of the articles with regard to relevance [29], while the rigour was judged using a tool designed by the Centre for Reviews and Dissemination for Systematic Reviews in the Social Sciences [54].

We employed the TAPUPAS appraisal tool developed by Pawson and colleagues [41] to judge the relevance of the studies included in the review. This tool has the merit of not restricting itself to validity but also including other pertinent issues related to rigour such as ethics and accessibility [61]. The seven questions in the TAPUPAS appraisal tool embody statements of good principles 


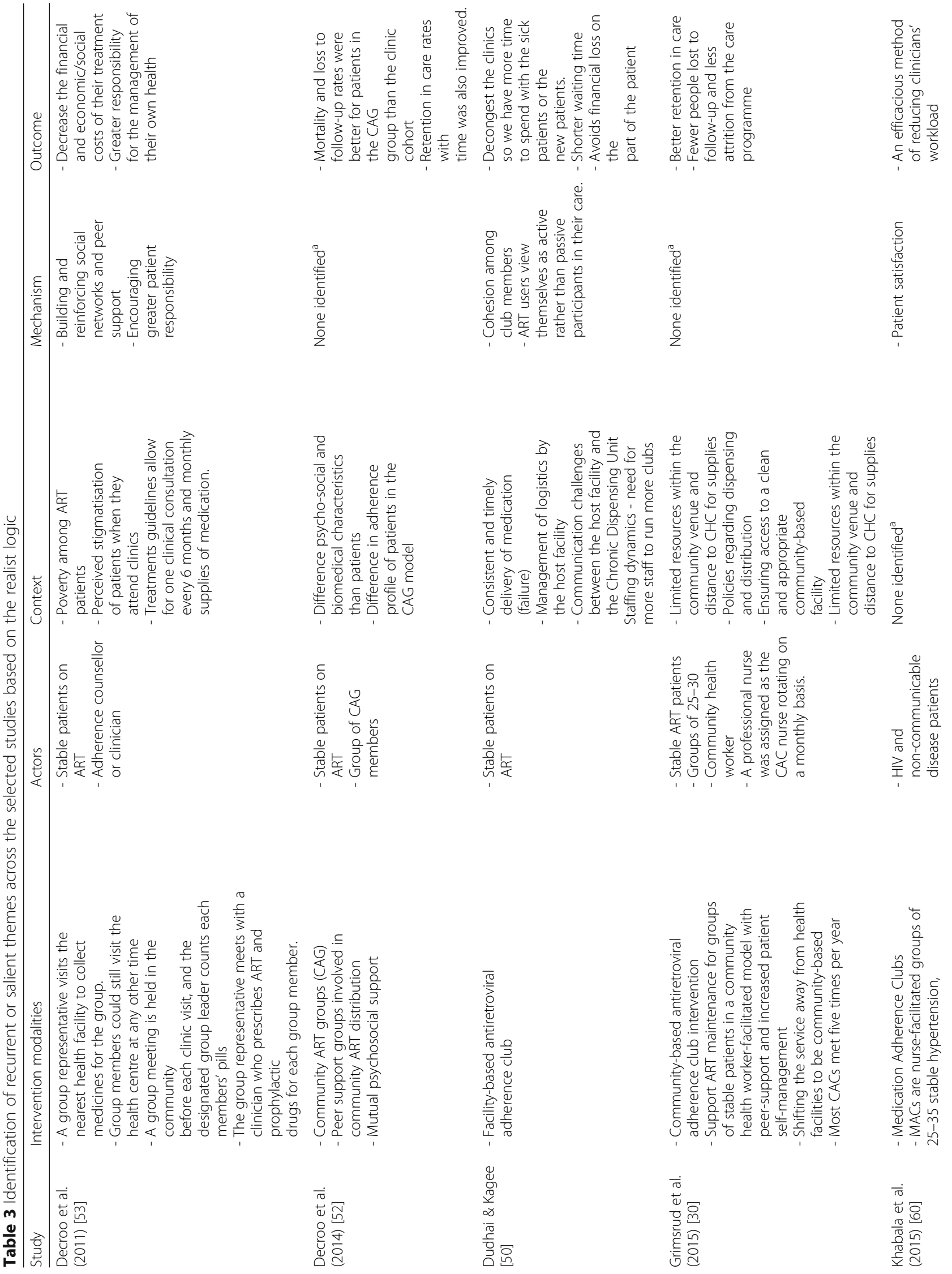




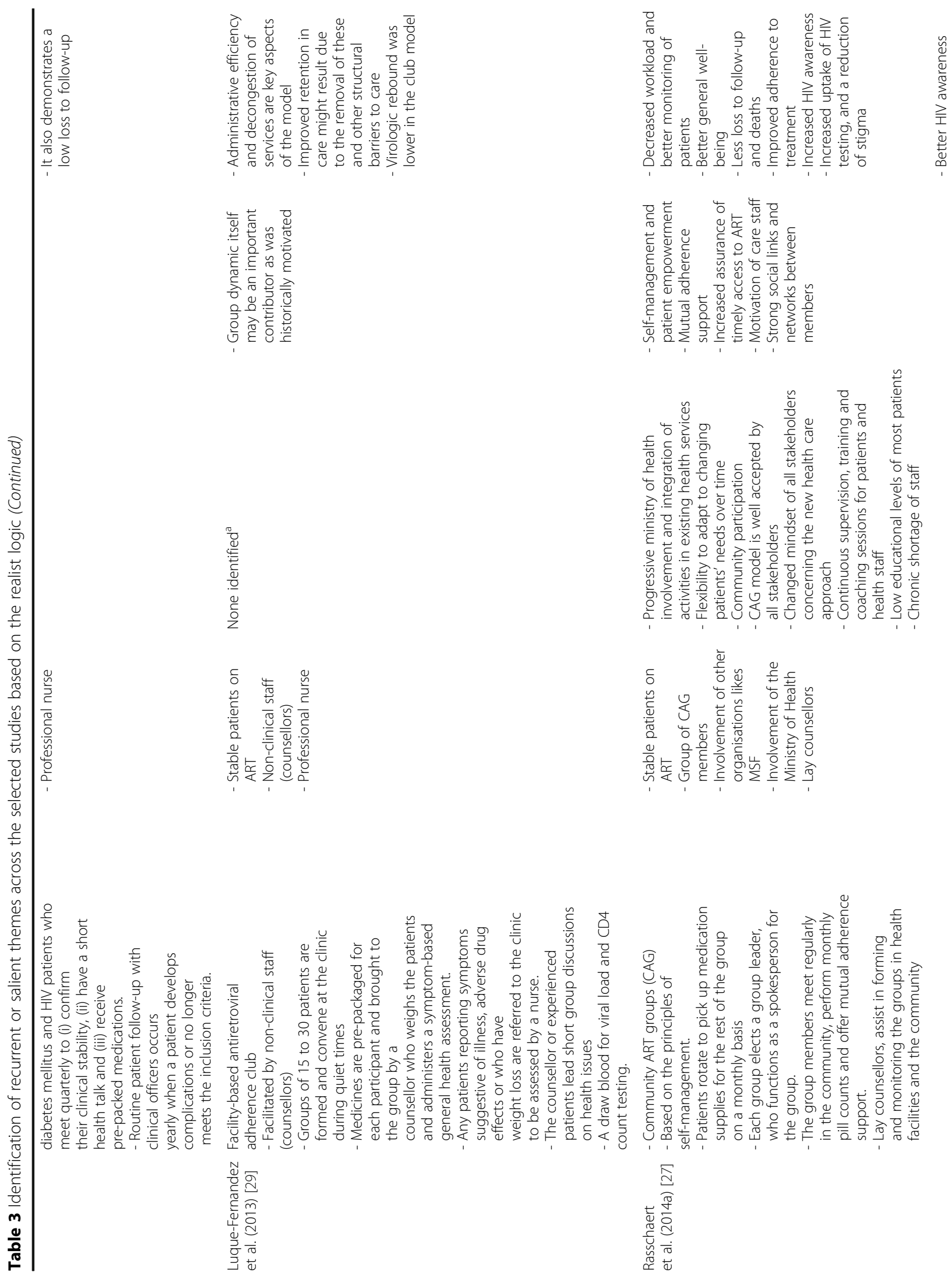




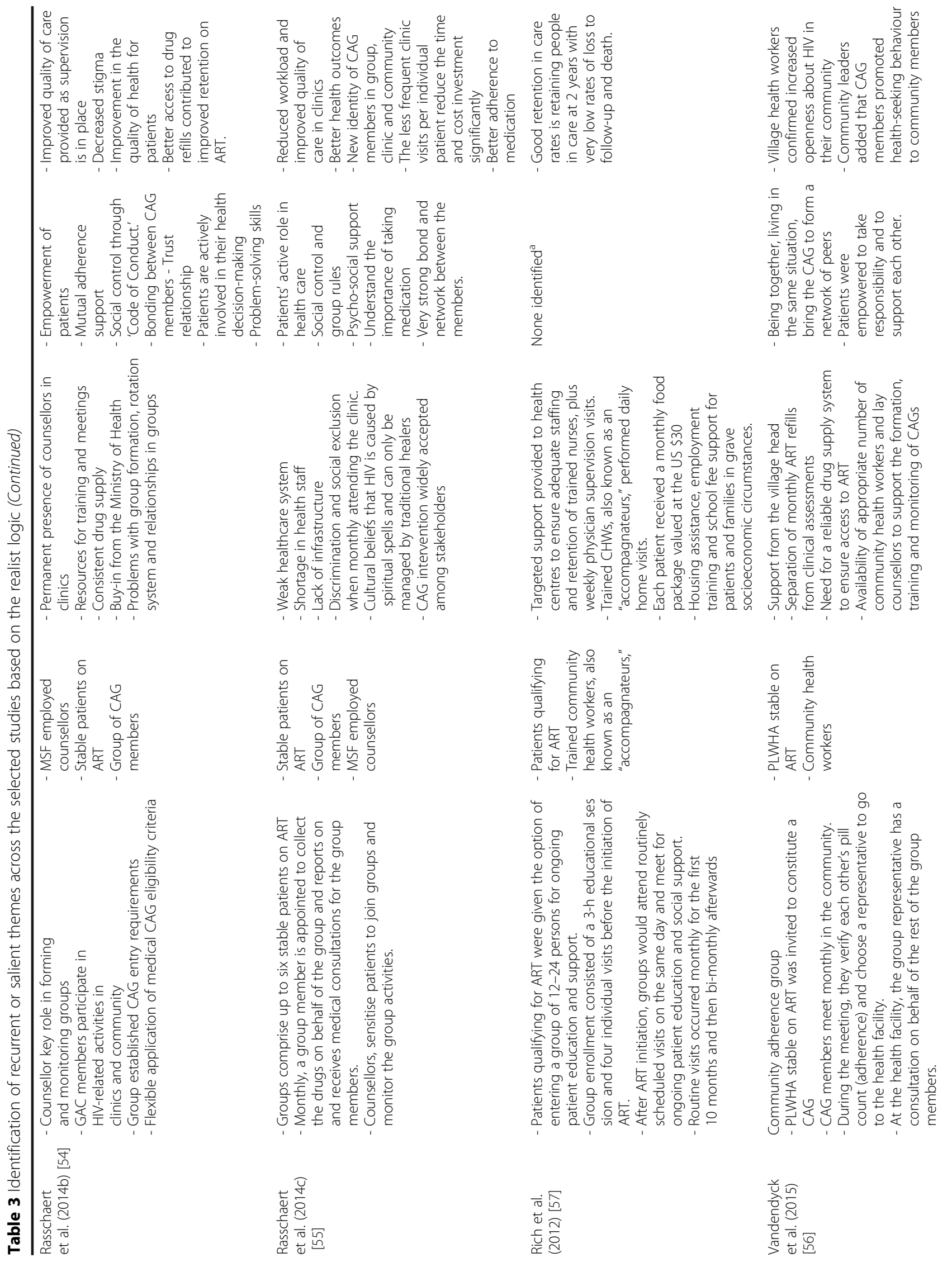




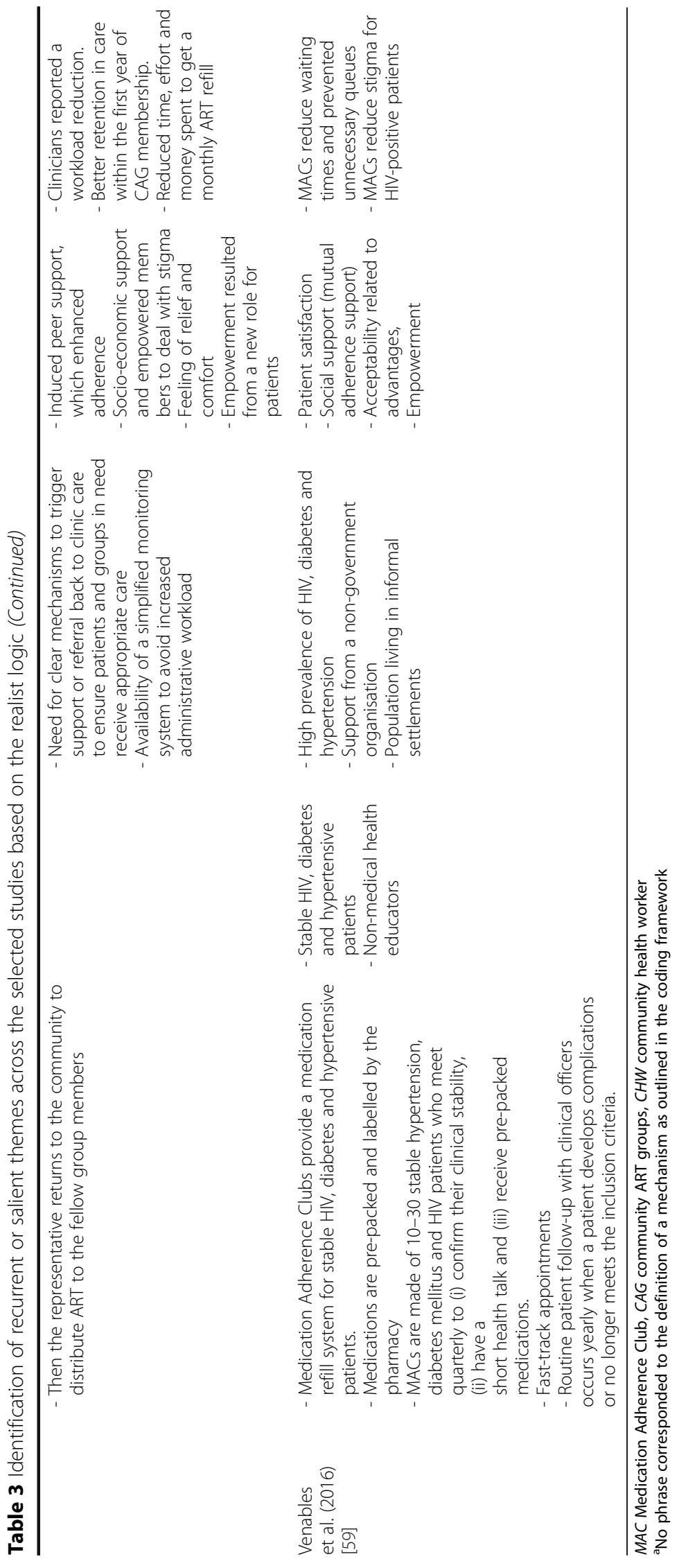


in research and its reporting. The attributes of the TAPUPAS appraisal tool include [48]:

- Transparency: is the process of knowledge generation open to outside scrutiny?

- Accuracy: are the claims made based on relevant and appropriate information?

- Purposive: are the methods used fit for purpose?

- Utility: are the knowledge claims appropriate to the needs of the reviewer?

- Propriety: has the research been conducted ethically and legally?

- Accessibility: is the research presented in a style that is accessible to the reviewer?

- Specificity: does the knowledge generated reach source-specific standards?

Overall, the studies that were included in the review met all the criteria stipulated in the TAPUPAS appraisal tool. The studies that were considered relevant for the review were then scrutinised for rigour: each study was assessed in terms of quality. Different evaluation tools were used for different studies based on the study designs. The screening was done using an adapted extraction/critical appraisal form to guide data extraction of studies in a systematic review of the health and social sciences [62]. (Additional file 2).

Based on this assessment process, we concluded that the findings obtained based on these studies could provide valuable and credible information on which sound conclusions could be drawn. In addition, the study is reported in accordance with the Preferred Reporting Items for Systematic Reviews and Meta-Analyses (PRISMA) guidelines (Additional file 3).

\section{Discussion}

This study is part of a large research project that applies the realist evaluation approach to study whether, how and why the adherence club intervention for the management stable patients on ART works. In realist research, the first step is to develop the initial programme theory. To do this, we first elicited the opinions and assumptions of the programme designers and managers (also called the folk theories). Based on these assumptions, we formulated tentative programme theories of the adherence club programme. In this paper, we sought to explore if the tentative programme theories that we formulated are compatible with research evidence (both applied research and basic research). We, therefore, conducted a narrative synthesis to identify and examine publications on group-based adherence models, looking at how those programmes were designed (especially their programme theory) and their effectiveness. We then assessed whether and how the studies produced evidence that could inform and refine our folk theories.
We found, not entirely unexpectedly, that the quantitative studies we identified did not provide sufficient information on the context and mechanisms that come into play to trigger the outcome. Although the four qualitative studies and the two mixed-method studies we found identified and described some of these elements, the association between these components and the explanation this may provide to account for the outcomes were not explored nor demonstrated. In other words, none of the studies provided evidence regarding the potential interplay between the aspects of the intervention, relevant context, significant actors, generative mechanisms and the outcomes of interest (causal explanation). This was identified by examining each of the identified studies through the ICAMO analytic tool. Consequently, they do not inform in an explicit manner how, why, for whom and in what circumstances that the evaluated group-based interventions work (or not).

Granting that the kind of studies we identified are useful in that they aim at assessing effectiveness, it would benefit the scientific community, policy makers and programme implementers more if details on the context and mechanisms of interventions designed to change behaviours were provided and if the evaluators would identify the causal processes underlying the observed results. This recommendation is echoed by calls made by implementation scientists to increase the use of theory to build knowledge about what works, where, and why [63]. Van Belle et al. also proposed that theory-driven approaches such as the realist evaluation approach have the potential to demonstrate the complex interplay between the components of a programme (or an intervention), relevant context conditions, actors involved, causal mechanisms and expected outcomes [64].

\section{Strengths and limitations}

Using the NS allowed us to preserve the integrity of the findings of the different types of studies that are reviewed, as the method does not seek to quantify findings that are narrative or qualitative in nature, nor does it attempt to describe the qualities present in numeric data [65]. Also, the use of categorical codes allowed for mediating between two forms of data which helped us to move from reported findings to higher levels of abstraction [65]. However, applying this method required us to rely on the descriptions of interventions supplied by the authors, and this could be a potential limitation of this approach.

Other limitations are related to the use of only two databases for the search of the studies for inclusion in the review. This introduces the possibility of missing out other studies that could be relevant to the review objective fitting the inclusion criteria. This potential loss was 
compensated to a certain extent by conducting snowballing of references along with the database search.

\section{Conclusion}

The types of studies identified in this review present a wide range in their evaluation approaches. Most of the quantitative-based approaches, unsurprisingly, provide little if any information on context and mechanisms. The qualitative studies somehow described context and mechanisms but did not go beyond description and conjecture. Because these studies did not identify nor demonstrate causal relationships, they did not provide information to guide the development of the initial programme theories underlying the ART adherence club interventions. In light of this challenges, we suggest that a way forward towards understanding how the adherence club intervention and other group-based adherence models work is to review the literature of other disciplines for possible theories on adherence to ART and/or chronic medications.

\section{Additional files}

Additional file 1: Table S1. Coding framework. (DOCX $13 \mathrm{~kb}$ )

Additional file 2: Table S2. Extraction/appraisal tool. (DOCX $16 \mathrm{~kb}$ )

Additional file 3: PRISMA 2009 Checklist. (DOC 64 kb)

\section{Acknowledgements}

Not applicable

\section{Funding}

The PhD from which this study emanated was funded by the Medical Research Council of South Africa and more specifically by the National Health Scholars Programme, provided for this purpose by the National Department of Health. This research was partially funded by an African Doctoral Dissertation Research Fellowship (ADDRF) award offered by the Africa Population and Health Research Center (APHRC) in partnership with the International Development Research Centre (IDRC).

\section{Availability of data and materials}

Because the study was a systematic review of published studies, the full references of these studies have been provided in the reference list.

\section{Authors' contributions}

BWW and FCM conceived the study. FCM and SVB conceptualised the paper. FCM designed and wrote the first draft of the manuscript. SVB and BM contributed to the development of the study. All authors reviewed and provided comments to improve the manuscript. All authors read and approved the final manuscript.

Ethics approval and consent to participate Not applicable

\section{Consent for publication}

Not applicable

\section{Competing interests}

The authors declare that they have no interests.

\section{Publisher's Note}

Springer Nature remains neutral with regard to jurisdictional claims in published maps and institutional affiliations.
Received: 1 November 2016 Accepted: 16 August 2017

Published online: 25 August 2017

\section{References}

1. Joint United Nations Programme on HIV/AIDS, Médecins Sans Frontières. Community-based antiretroviral therapy delivery. Joint United Nations Programme on HIV/AIDS; 2015. Available from: http://www.unaids.org/sites/ default/files/media_asset/20150420_MSF_UNAIDS_JC2707.pdf. Accessed 7 Mar 2016

2. McCoy D, Chopra M, Loewenson R, Aitken J-M, Ngulube T, Muula A, et al. Expanding access to antiretroviral therapy in sub-saharan Africa: avoiding the pitfalls and dangers, capitalizing on the opportunities. Am Public Health Assoc. 2005;95(1):18-22. doi:https://doi.org/10.2105/AJPH.2004.040121.

3. Hiko D, Jemal A, Sudhakar M, Kerie M, Dejene T. Determinants of noncompliance to antiretroviral therapy among adults living with HIV/AIDS: a systematic review. JBI Database Syst Rev Implementation Rep. 2012;10(14 Suppl):214-27.

4. Stricker S, Fox K, Baggaley R, Negussie E, de Pee S, Grede N, et al. Retention in care and adherence to ART are critical elements of HIV care interventions. AIDS Behav. 2013;18(S5):465-75. doi:https://doi.org/10.1007/s10461-0130598-6.

5. Assefa Y, Alebachew A, Lera M, Lynen L, Wouters E, Van Damme W. Scaling up antiretroviral treatment and improving patient retention in care: lessons from Ethiopia, 2005-2013. Glob Health. 2014;3(10):43. doi:https://doi.org/10. 1186/1744-8603-10-43

6. Haberer JE, Sabin L, Amico KR, Orrell C, Galárraga O, Tsai AC, et al. Improving antiretroviral therapy adherence in resource-limited settings at scale: a discussion of interventions and recommendations. J Int AIDS Soc. 2017;20 doi:https://doi.org/10.7448/IAS.20.1.21371.

7. Bateman C. MSF again paves the way with ART. S Afr Med J. 2013;103(2):713. doi:https://doi.org/10.7196/SAMJ.6666.

8. Grimsrud A, Balkan S, Casas EC, Lujan J. Outcomes of antiretroviral therapy over a 10-year period of expansion: a multicohort analysis of African and Asian HIV programs. J Acquir Immune Defic Syndr. 2014;67(2):e55-66. doi: https://doi.org/10.1097/QAl.0000000000000268.

9. Fox M, Rosen S. Patient retention in antiretroviral therapy programs up to three years on treatment in sub-Saharan Africa, 2007-2009: systematic review. Tropical Med Int Health. 2010;15(s1):1-15.

10. UNAIDS. 90-90-90 An ambitious treatment target to help end the AIDS epidemic. 2014;40. Available from http://www.unaids.org/en/resources/ documents/2017/90-90-90. Accessed 23 Mar 2017.

11. Suthar A, Rutherford G, Horvath T, Doherty M, Negussie E. Improving antiretroviral therapy scale-up and effectiveness through service integration and decentralization. AIDS. 2014;28(Suppl 2):S175-85. doi:https://doi.org/10. 1097/QAD.0000000000000259.

12. Wouters E, Masquillier C, Ponnet K, le Roux Booysen F. A peer adherence support intervention to improve the antiretroviral treatment outcomes of HIV patients in South Africa: the moderating role of family dynamics. Soc Sci Med. 2014;113:145-53.

13. Ford N, Mills E. Simplified ART delivery models are needed for the next phase of scale-up. PLoS Med. 2011;8(7):e1001060. doi:https://doi.org/10. 1371/journal.pmed.1001060.

14. Bemelmans M, Baert S, Goemaere E, Wilkinson L, Vandendyck M, Cutsem G, et al. Community supported models of care for people on HIV treatment in sub Saharan Africa. Tropical Med Int Health. 2014;19(8):968-77. doi:https:// doi.org/10.1111/tmi.12332.

15. Mills EJ, Lester R, Thorlund K, Lorenzi M, Muldoon K, Kanters S, et al. Interventions to promote adherence to antiretroviral therapy in Africa: a network meta-analysis. Lancet HIV. 2014;1(3):e104-11. doi:https://doi.org/10. 1016/S2352-3018(14)00003-4

16. International AIDS Society. Differentiated care for HIV: A decision framework for Antiretroviral therapy. Durban; 2016. Available from: http://www. differentiatedcare.org/Portals/0/adam/Content/yS6M-GKB5EWs_uTBHk1C1Q/ File/Decision\%20Framework.pdf. Accessed 22 Aug 2017.

17. Médecins Sans Frontières, Southern Africa Medical Unit. Reaching Closer to Home Progress implementing community-based and other adherence strategies supporting people on HIV treatment. Médecins Sans Frontières; 2013. Available from: http://www.msf.org/sites/msf.org/files/reaching_ closer_home.pdf. Accessed 09 June 2015.

18. World Health Organization. Consolidated Guidelines on the Use of Antiretroviral Drugs for Treating and Preventing HIV Infection 2016 
Recommendations for a public health approach. Switzerland; 2016. Available from: http://www.who.int/hiv/pub/arv/arv-2016/en/.

19. Campion EW. Treating millions for HIV - the adherence clubs of Khayelitsha. N Engl J Med. 2015;372:301-3. doi:https://doi.org/10.1056/NEJMp1414213.

20. Duncombe C, Rosenblum S, Hellmann N, Holmes C, Wilkinson L, Biot M, et al. Reframing HIV care: putting people at the centre of antiretroviral delivery. Tropical Med Int Health. 2015;20(4):430-47. doi:https://doi.org/10.1111/tmi.12460.

21. Simoni JM, Amico KR, Pearson CR, Malow R. Strategies for promoting adherence to antiretroviral therapy: a review of the literature. Curr Infect Dis Rep. 2008;10(6):515-21.

22. Apondi R, Bunnell R, Awor A, Wamai N, Bikaako-Kajura W, Solberg P, et al. Home-based antiretroviral care is associated with positive social outcomes in a prospective cohort in Uganda. J Acquir Immune Defic Syndr. 2007; 44(1):71-6.

23. Root $R$, Whiteside $A$. A qualitative study of community home-based care and antiretroviral adherence in Swaziland. J Int AIDS Soc. 2013;16(1):17978. doi:https://doi.org/10.7448/ias.16.1.17978.

24. Muñoz M, Finnegan K, Zeladita J, Caldas A, Sanchez E, Callacna M, et al. Community-based DOT-HAART accompaniment in an urban resource-poor setting. AIDS Behav. 2010;14(3):721-30. doi:https://doi.org/10.1007/s10461009-9559-5.

25. Mukherjee JS, Barry D, Weatherford RD, Desai IK, Farmer PE. Communitybased ART programs: sustaining adherence and follow-up. Curr HIV/AIDS Rep. 2016;13:359-66. doi:https://doi.org/10.1007/s11904-016-0335-7.

26. Franke MF, Kaigamba F, Socci AR, Hakizamungu M, Patel A, Bagiruwigize $E_{i}$ et al. Improved retention associated with community-based accompaniment for antiretroviral therapy delivery in rural Rwanda. Clin Infect Dis. 2013;56 doi:https://doi.org/10.1093/cid/cis1193.

27. Rasschaert F, Telfer B, Lessitala F, Decroo T, Remartinez D, Biot M, et al. A qualitative assessment of a community antiretroviral therapy group model in Tete, Mozambique. PLoS One. 2014;9(3):e91544. doi:https://doi.org/10. 1371/journal.pone.0091544.

28. Decroo T, Rasschaert F, Telfer B, Remartinez D, Laga M, Ford N. Communitybased antiretroviral therapy programs can overcome barriers to retention of patients and decongest health services in sub-Saharan Africa: a systematic review. Int Health. 2013;5(3):169-79. doi:https://doi.org/10.1093/inthealth/iht016.

29. Luque-Fernandez MA, Van Cutsem G, Goemaere E, Hilderbrand K, Schomaker M, Mantangana N, et al. Effectiveness of patient adherence groups as a model of care for stable patients on antiretroviral therapy in Khayelitsha, Cape Town, South Africa. PLoS One. 2013;8(2):e56088. doi: https://doi.org/10.1371/journal.pone.0056088.

30. Grimsrud A, Sharp J, Kalombo C, Bekker L-G, Myer L. Implementation of community-based adherence clubs for stable antiretroviral therapy patients in Cape Town, South Africa. J Int AIDS Soc. 2015;18(1). doi: https://doi.org/ 10.7448/IAS.18.1.19984

31. Wouters E, Damme W, van Rensburg D, Masquillier C, Meulemans H. Impact of community-based support services on antiretroviral treatment programme delivery and outcomes in resource-limited countries: a synthetic review. BMC Health Serv Res. 2012;12(1):194. doi:https://doi.org/10. 1186/1472-6963-12-194.

32. Chen HT. Theory-driven approach for facilitation of planning health promotion or other programs. Can J Program Eval. 2003;18(2):91-113.

33. Simoni JM, Rivet Amico K. Smith L, Nelson K. Antiretroviral adherence interventions: translating research findings to the real world clinic. Curr HIV/ AIDS Rep. 2010;7(1):44-51. doi:https://doi.org/10.1007/s11904-009-0037-5.

34. Kaufman MR, Cornish F, Zimmerman RS, Johnson BT. Health behavior change models for HIV prevention and AIDS care: practical recommendations for a multi-level approach. J Acquir Immune Defic Syndr. 2014;66(Suppl 3):S250-8. doi:https://doi.org/10.1097/QAI. 0000000000000236 .

35. Funnell SC, Rogers PJ. Purposeful program theory: Effective use of theories of change and logic models. San Francisco: John Wiley \& Sons; 2011.

36. Nebot Giralt A, Nöstlinger C, Lee J, Salami O, Lallemant M, Ouma O, et al. Understanding the acceptability and adherence to paediatric antiretroviral treatment in the new formulation of pellets (LPV/r): the protocol of a realist evaluation. BMJ Open. 2017;7:e014528. doi:https://doi.org/10.1136/bmjopen2016-014528.

37. Pawson R, Tilley N. Realistic evaluation. 2nd ed. London: SAGE Publications; 1997.

38. Mukumbang FC, Van Belle S, Marchal B, Van Wyk B. Exploring 'generative mechanisms' of the antiretroviral adherence club intervention using the realist approach: a scoping review of research-based antiretroviral treatment adherence theories. BMC Public Health. 2017;17:38. doi:https://doi.org/10. 1186/s12889-017-4322-8.

39. Dalkin SM, Greenhalgh J, Jones D, Cunningham B, Lhussier M. What's in a mechanism? Development of a key concept in realist evaluation. Implement Sci. 2015;10:1-7. doi:https://doi.org/10.1186/s13012-015-0237-x.

40. Van Belle S. Accountability in sexual and reproductive health How relations between INGOs and state actors shape public accountability A study of two local health systems in Ghana Sara. Thesis submitted in fulfilment for the award of the degree of Doctor. University of London; 2013.

41. Mukumbang FC, Van Belle S, Marchal B, Van Wyk B. Realist evaluation of the antiretroviral treatment adherence club programme in selected primary healthcare facilities in the metropolitan area of Western Cape Province, South Africa: a study protocol. BMJ Open. 2016;6(4):e009977. doi:https://doi. org/10.1136/bmjopen-2015-009977.

42. Wong G, Westhorp G, Pawson R, Greenhalgh T. Realist Synthesis: Rameses training materials, 2013. http://www.ramesesproject.org/media/Realist_ reviews_training_materials.pdf. Accessed 24 Nov 2015.

43. Popay J, Roberts H, Sowden A, Petticrew M, Arai L, Rodgers M, et al. Guidance on the conduct of narrative synthesis in systematic reviews. doi: 10.13140/2.1.1018.4643: A Product from the ESRC Methods Programme; 2006

44. Ryan G, Bernard H. Techniques to identify themes. Field Method. 2003;15(1): 85-109.

45. Pawson R, Greenhalgh J, Brennan C, Glidewell E. Do reviews of healthcare interventions teach us how to improve healthcare systems? Soc Sci Med. 2014;114:129-37. doi:https://doi.org/10.1016/.socscimed.2014.05.032.

46. Arai L, Britten N, Popay J, Roberts H, Petticrew M, Rodgers M, et al. Testing methodological developments in the conduct of narrative synthesis: a demonstration review of research on the implementation of smoke alarm interventions. Evid Amp Policy J Res Debate Pract. 2007;3(3):361-83. doi: https://doi.org/10.1332/174426407781738029.

47. Stern C, Jordan Z, McArthur A. Developing the review question and inclusion criteria. Am J Nurs. 2014;114(4):53-6. doi:https://doi.org/10.1097/01. NAJ.0000445689.67800.86.

48. Pawson R, Boaz A, Grayson L, Long A, Barnes C. Types and quality of knowledge in social care. London: Social Care Institute for Excellence; 2003.

49. Grimsrud A, Bygrave H, Doherty M, Ehrenkranz P, Ellman T, Ferris R, et al. Reimagining HIV service delivery: the role of differentiated care from prevention to suppression. J Int AIDS Soc. 2016;19(1):21484. doi:https://doi. org/10.7448/IAS.19.1.21484

50. Mukumbang FC, Van Belle S, Marchal B, van Wyk B. Towards developing an initial Programme theory: Programme designers and managers assumptions on the antiretroviral treatment adherence Club Programme in primary health care facilities in the metropolitan area of Western Cape Province, South Africa. PLoS One. 2016;11(8):e0161790. doi:https://doi.org/10.1371/ journal.pone.0161790.

51. Blackstone A. Principles of sociological inquiry-qualitative and quantitative methods. New York: Saylor Foundation; 2012.

52. Decroo T, Koole O, Remartinez D, Santos N, Dezembro S, Jofrisse M, et al. Four-year retention and risk factors for attrition among members of community ART groups in Tete, Mozambique. Tropical Med Int Health. 2014;19(5):514-21. doi:https://doi.org/10.1111/tmi.12278.

53. Decroo T, Telfer B, Biot M, Maïkéré J, Dezembro S, Cumba L, et al. Distribution of antiretroviral treatment through self-forming groups of patients in Tete province, Mozambique. J Acquir Immune Defic Syndr. 2011; 56(2):e39-44. doi:https://doi.org/10.1097/QAl.0b013e3182055138.

54. Rasschaert F, Decroo T, Remartinez D, Telfer B, Lessitala F, Biot M, et al. Sustainability of a community-based anti-retroviral care delivery model a qualitative research study in Tete, Mozambique. J Int AIDS Soc. 2014;17(1). doi: https://doi.org/10.7448/IAS.17.1.18910.

55. Rasschaert F, Decroo T, Remartinez D, Telfer B, Lessitala F, Biot M, et al. Adapting a community-based ART delivery model to the patients' needs: a mixed methods research in Tete, Mozambique. BMC Public Health. 2014; 14(1):364. doi:https://doi.org/10.1186/1471-2458-14-364.

56. Vandendyck M, Motsamai M, Mubanga M. Community-based ART resulted in excellent retention and can leverage community em-powerment in rural Lesotho, a mixed method study. HIV/AIDS Res Treat Open J. 2015;2(2):4450. doi:10.17140/HARTOJ-2-107.

57. Rich ML, Miller AC, Niyigena P, Franke MF. Excellent clinical outcomes and high retention in care among adults in a community-based HIV treatment 
program in rural Rwanda. J Acquir Immune Defic Syndr. 2012;59:e35-42. doi:https://doi.org/10.1097/QAl.0b013e31824476c4.

58. Dudhia R, Kagee A. Experiences of participating in an antiretroviral treatment adherence club. Psychol Health Med. 2015;20(4):488-94. doi: https://doi.org/10.1080/13548506.2014.953962.

59. Venables E, Edwards JK, Baert S, Etienne W, Khabala K, Bygrave H. "They just come, pick and go." The Acceptability of Integrated Medication Adherence Clubs for HIV and Non Communicable Disease (NCD) Patients in Kibera, Kenya. PLoS One. 2016;11:e0164634. doi:https://doi.org/10.1371/journal. pone. 0164634 .

60. Khabala KB, Edwards JK, Baruani B, Sirengo M, Musembi P, Kosgei RJ, et al. Medication Adherence Clubs: a potential solution to managing large numbers of stable patients with multiple chronic diseases in informal settlements. Tropical Med Int Health. 2015;20(10):1265-70. doi:https://doi. org/10.1111/tmi.12539.

61. Porter S. Validity, trustworthiness and rigour: reasserting realism in qualitative research. J Adv Nurs. 2007;60(1):79-86.

62. Petticrew M, Roberts H. Wiley InterScience (Online service). Systematic reviews in the social sciences : a practical guide. Oxford: Blackwell Publications; 2006.

63. Bauer MS, Damschroder L, Hagedorn H, Smith J, Kilbourne AM, Titchen A. An introduction to implementation science for the non-specialist. BMC Psychol. 2015;3:32. doi:https://doi.org/10.1186/s40359-015-0089-9.

64. Van Belle S, van de Pas R, Marchal B. Towards an agenda for implementation science in global health: there is nothing more practical than good (social science) theories. BMJ Glob Heal. 2017;2(2):e000181. doi: https://doi.org/10.1136/bmjgh-2016-000181.

65. Harden A, Thomas J. Methodological issues in combining diverse study types in systematic reviews. Int J Soc Res Methodol. 2005;8(3):257-71. doi: https://doi.org/10.1080/13645570500155078.

\section{Submit your next manuscript to BioMed Central and we will help you at every step:}

- We accept pre-submission inquiries

- Our selector tool helps you to find the most relevant journal

- We provide round the clock customer support

- Convenient online submission

- Thorough peer review

- Inclusion in PubMed and all major indexing services

- Maximum visibility for your research

Submit your manuscript at www.biomedcentral.com/submit 